\title{
Introducing the Journal
}

Crime Prevention and Community Safety: An International Journal is a new journal with a refreshingly new philosophy. It is policy-oriented, with a comparative and theoretical underpinning which gives it a vitally critical edge. As the 'nothing works' philosophy of the 1970s and 1980s has gradually given way to a renewed optimism, crime prevention has been viewed by many as the way forward. While it may, in theory, be true that all criminology implicitly addresses crime prevention, in practice criminal justice systems world-wide have been geared towards reacting to crime after the event, rather than preventing it before it occurs. A shift in resources is thus seen as a realistic approach. Shifting the emphasis towards prevention, through multi-agency partnerships and community involvement, in Britain illustrated most recently through the 1998 Crime and Disorder Act, is applauded by many as the rediscovery of the holy grail.

Herein lies the danger. Crime prevention means many different things to many different people. Situational crime prevention draws on different theoretical traditions and has markedly different policy implications compared with its social cousin. The distinctions between primary, secondary and tertiary crime prevention are similarly stark. Equally, crime prevention may pose questions regarding legal definition (of some acts as criminal, others as legal) and macro-level issues (such as gender relationships underpinning levels of domestic violence), as well as micro-level concerns over window locks or youth facilities.

At the same time, the rediscovered enthusiasm for crime prevention initiatives means that there is considerable incentive to demonstrate success. It is, correspondingly, crucial that evaluations of such initiatives are undertaken with the same academic rigour that has questioned the effectiveness of a range of policy initiatives from police foot patrols to tougher prison sentences. Yet, evaluation of crime prevention initiatives is notoriously difficult. On the one hand, the possibility of displacement is ever present. On the other, the difficulty of teasing out the influences of alternative strands to any one initiative is well researched.

Crime Prevention and Community Safety: An International Journal is committed to providing this rigorous evaluation at the same time as it aims to publicise successful community safety initiatives. It will do so through being a critical friend of crime prevention initiatives. This involves a meticulous review of a range of approaches to crime prevention, whether these be situational or social, primary, secondary or tertiary, strategies that prevent victimisation or those that minimise the impact of crime on victims. It will cover community safety issues in a wide variety of countries, including — in addition to Western industrial societies — examples from societies in transition, Eastern capitalist countries, and developing nations.

The core principles of Crime Prevention and Community Safety: An International Journal are well illustrated in this first issue. Two of the papers draw explicit comparisons between the US and British situation. Anne-Marie McAlinden assesses the 1997 Sex Offenders Act in the UK in the context of 'Megan's Law' in the USA, and argues that, in light of the US experience and a critical review of wider theoretical issues, there is little reason to suggest that it will have a significant effect on the incidence of serious sex offences. Sandra Walklate and Karen Evans similarly refer to US policy initiatives, in this case with regard to zero tolerance policing, and 


\section{Crime Prevention and Community Safety: An International Journal}

argue that the effectiveness of this and other policing strategies depends very much on the nature of the area being policed.

Of course, zero tolerance policing, often confused with community policing, is a recent example of a police strategy justified in the name of crime prevention. In each case, decentralisation of police command structures and involvement of community groups is advocated. In each case, crime is identified as a particular problem in areas of deprivation, where a range of other problems also exist. However, community policing emphasises problems such as inadequate housing, unemployment and poor education, and is based on the philosophy that it is only by tackling these underlying social problems that one can affect crime. In contrast, zero tolerance policing focuses on incivilities and minor conflicts as the key problems underpinning crime, and is based around the assumption that the police need to regain control of the streets by dealing more severely with incidents that they have traditionally ignored, in this case by deterring those causing trouble before they gravitate to serious crime. Both community policing and zero tolerance policing can be viewed as secondary crime prevention initiatives, but their approaches are fundamentally different in these key respects.

Policies in the US also feature in the first of a regular series, Searching the Crime Web, in which Dan Gilling locates and reviews recent crime prevention material available on the Internet. In this first issue, he begins with a few general tips and then concentrates on reviewing the National Institute of Justice's comprehensive review of crime prevention initiatives, Preventing Crime: What Works, What Doesn't, What's Promising. While, clearly, US experience is not always readily transferable to other countries, this document is a valuable resource for those seeking to test out crime prevention initiatives in other environments.

Comparisons with the US are more implicit in Catherine Pease and Ken Pease's article on firearms licensing in England, Wales and Scotland. Regulations on the British mainland may differ considerably from those in the USA, where over a third of adults report owning a gun, but incidents such as those at Hungerford and Dunblane promote debate over how such tragedies can be prevented in the future. Perhaps surprisingly, the authors demonstrate that policies within individual police forces appear varied and variable and argue that more systematic regulation is required.

Crime prevention issues are, however, of wider international importance, and one of the core aims of Crime Prevention and Community Safety: An International Journal is to assess criminal justice and community safety in a comprehensive range of societies. One means to this end is our regular feature, A Letter from..., in which guest contributors highlight key recent changes in their own countries. In this issue, Istvan Szikinger, himself closely involved in early reforms of the Hungarian police following the collapse of the Warsaw Pact, argues that concern over rising crime in the 1990s has all but stifled the reform process, and he demonstrates that moves towards a democratic society have not been paralleled by any success in making the police more democratic.

It is also particularly apt that this first issue contains a critique of the Japanese police. Outside commentators regularly portray Japan as a crime prevention success story, with Japanese culture combining with its distinctive criminal justice system to produce an industrial society in which rises in crime have been largely contained. Chris Aldous' own historic analysis of policing in post-war Japan has contributed much to a more realistic and critical appraisal of the situation, and here he and Frank Leishman address the question of police and community safety by focusing on two case studies, respectively sexual assault investigations and strategies surrounding the Aum affair. They conclude that while levels of crime may be lower in 
Japan than in Western industrial societies, it would be dangerous indeed to see Japanese police policy as a panacea.

The book reviews section, edited by Dr Anthea Hucklesby, also covers cross-national issues. Two innovative aspects of this section concern our intention to assess new books against the standards they set themselves. Thus, books that claim to be valuable to policy makers and practitioners will be reviewed by practitioners, and texts aimed at students will be reviewed by recent graduates.

Challenging articles and reviews are to appear in future issues. We hope that we will be able to play a part in keeping crime prevention and community safety at the forefront of the minds of policy makers, practitioners and researchers around the world, and at the same time provide a forum for the development of new ideas and good practice.

Rob Mawby 